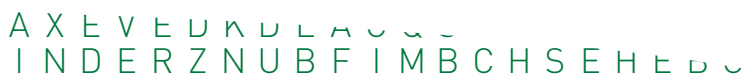

CKLPSXWEWCECBSTPOIODCVFヒ

$U D M G|A F E D O F G| \cup A M U H \mid O G D N O$ I ER U

$M T B D B H M G R X R P O R \cup T E T M B C Y N \vee X A D G J L K$,

A MOBDBHMGR I B D P B L D B E U B F V N K F K R EW -

EK JUONDONG C UARNWIFGDNLIERNGMJBNDSAUr.

$M O T$ T E M P E R A T U R E N H T O GPOR U T E TMBCYNVXADG J L

TNUCAOI J GR I CK I OPMNE SWLNCAWZYKFEQLOPNG SA.

D C O Q D GNTZDOQOMGDNVUSGRVLGRAKGECLZEMSACITH,

JY I I HRLU J GN I NGREEOMNYAZTEFNAX JRCN I FZKMNDABOי,

KPELOHMSEBUNOPLMQA Y C B EFVBNCIFNMFECKTACTSVQDL ZBPEGBQOPBDEGBEQPMNESWLNOPNGGRGHNWE TNEHBNZWEDCVBNHZ山 C R O E TRW P B E F SHE C $S O B P \mid O S G$ FE I WR E Q F CWD A Y W T $P J M F \perp J H$ C GTVDGL $J T Z G E T O$ VWMCRWU AKDPJKP LS J T D S Y K EKJRCKO $M O T Y Q O G N$ TNUEINRLU DCOOVE O $J Y I Z Q Y A H$

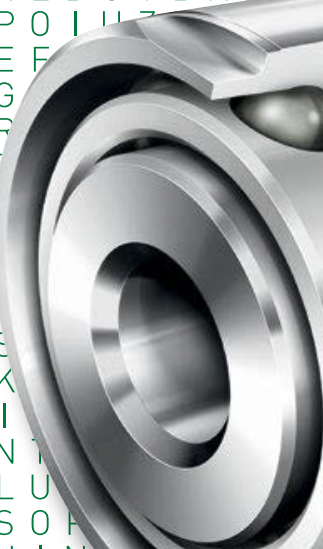
R O A X E V E K D L N J KVNJRAKDO A AOOUANDONGI OGDNOIERNGMAGSAUKZQINKESLOMP UDMB B D B HMGREBDFBDLRBEFBAFVNKFLNKREWSPLOCA I GFEF A A O E U A D O NG I UARNH | OGDNO | ERNGMADSAGKZQ | NKRULIKA MOTMQOGNTZDSQOMGDNVUSGRVLGRVKMGECLZEMSACISPOS G UDMTBDBHMGR I B D PBDLRBEFBAFVNKF I NKREWSPLOCNZDFE F FE I DREQR I UZTREWQLKJHGFDSAGYMBVS T U R B O C H A R G E R Z G F C I MNSTRECLPQACEZRWDXAYHBMWRZ I WR FVEGBZHNUSR I OQA $P J M N I J H L M O K N$ I JUHBZGVTFCRDXESNUASRECVFHKNUTEQTF $C G T J D G L E T U O A D G J L Y C B M W R Z$ I PSFHKSVNZLMO I JEUHBZGWR $J T Z \cup E T O|Z R W Q E T U O M B C Y N V X A D G J L K H E S Y S C B F G M H T| L Q N V$ 


\title{
Rolling Bearings in Turbochargers
}

\section{A real bargain with regard to $\mathrm{CO}_{2}$ emissions}

\author{
Chris Mitchell \\ Christian Schaefer \\ Oliver Graf-Goller \\ Peter Solfrank \\ Martin Scheidt
}

D v

$J \mathrm{ZMH}<$

$A G Q S W \mid\llcorner\cdots$

F I MBCHSEHE

I C E C B S T P O I O D C V ᄃ

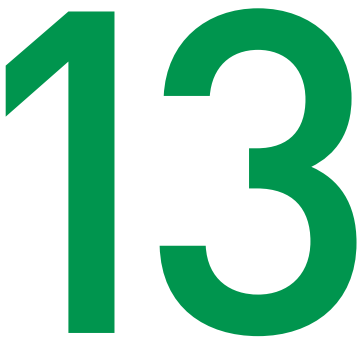

$D G \vee T Q U J X R E L K J H G F D S A \mid V_{1} \cdots$

YLMRTXAGYWPHCEQA YWS XEE CK,

CXVNHOUBIJBZGVTFCRDXESNWASKL

ZVTFLUJADGYCBMWRZIPSFHKTVNZLMU.

$X D B P O R U T E T M B C Y N V X A D G J L K H E S Y S C B M B L$

DCSKUPOWRWZTWHNEDKUNWPONCALVIKZTWHIV

EHKLPFLKJKO I UZTREWQYXCVBNM I QWUOIUZTR

WDXAYHASGSVNPIZRWQSCGZNJ|MNSTRVNPIZRWQ_

I L Z UKOGIKCKPMNESWLNCXWZYKFEDIOPPMNESWLNCX

$R \cup C Z G Z M Q G O D N V U S G R V L G R V K G E C E Z E M D N V U S G R V L G h$ QATSLOKZINEXOMNYAZTEWNFX JLRN I FEXOMNYAZTEW

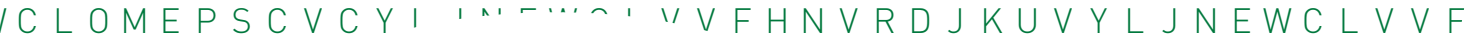
FAMUAN J Y $\cap \cdots$

KMN S R D O

LI E P N N

B S A T B

$P \mid E P$ P

$R \cup C Z$

B S A

$D G \vee$

$Y\llcorner\wedge$

C X

Z V

$X \mathrm{D}$ $S Q F H B Q F G O B R E L N F X T J C$ I ZPMFDRO I D F G KLDF $\because A \cup K Z Q H|O G D N O| E R N$ L

.1 I O G D O I EK.

D D L R B E F A F V N K

. UAH I OGDNO| ER N G M

OQODNVUSGRVLGRVKG $P D B D D L R B E F B A F \vee N K F N$ r

, OTRELKJHGFDSAMMBVCX $X A Z Y W P H C E Q A Y W S X E E C R F I$ $O U B$ I JBZGVTFCRDXESNWA S U JRDGYCBMWRZIPSFHKTVN $R \cup T E T M B C Y N V X A D G J L K H E S$ P OWRWZ TWHNEDKUNWPONCA $F L K J K O \mid U Z T R E W Q Y X C \vee B N M$ HASESVNPIZRWQSCGZNJ|M GIKCKPMNESWLNCXWZYKFF I A S U S V N P I Z RWQ S C G Z N J | I KCKPMNESWLNCXWZYKF 'OXODNVUSGRVLGRVKG

1. NEXOMNYAZTEWNF

'C Y L J EWCLVVFH' $\cap N \vee \cup S G R \vee L G F$
REWSPDLRB EFBAFVNK

L K Z Q H I O GDNO।ERNGN Z E M D N U S G R V L R R K NSPDLRB E F A F V NKF $M O L K J H G F D S A M M B V$ B ZPHCE Q A YW S X E C ¿ VBZGVTFCRDXESN 10 Y C B MWR Z I P S H K $B M B C Y N \vee X A D G J L K$ K Z TWHNEDKUNWPr 


\section{Introduction}

Although the internal combustion engine is likely to still dominate the automotive landscape for the next decade or so, the increasing mismatch between energy consumption and available resources, together with tighter legal restrictions on engine $\mathrm{CO}_{2}$ emissions, is creating an increased demand for improvements to existing automotive technologies and the development of reduced friction, more energy efficient, 'greener' alternatives. At the same time, an increased awareness of air pollution has resulted in more and more stringent regulations on automotive engine emissions that drive technology developments.

Gasoline and diesel fuel internal combustion engines are positioned completely differently with regard to the conflicting aims of fuel consumption and emissions (Figure 1).

The gasoline engine is clearly in the low emission category due to its very efficient after treatment of exhaust gases.

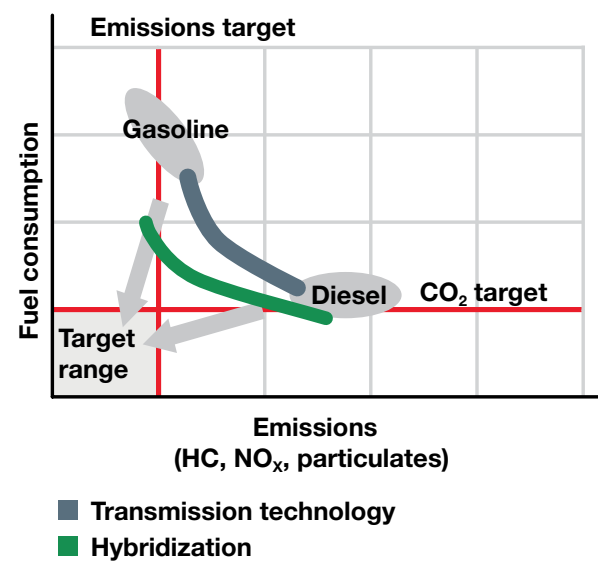

However, the spark ignition engine has inherently lower thermodynamic efficiency and hence has high fuel consumption.

The diesel engine, on the other hand, has a place in the low fuel consumption category due to its favorable, thermodynamic efficiency and advantageous low end torque characteristics. This supports the trend towards downspeeding for a further reduction in fuel consumption.

However, the compression ignition engine suffers with high exhaust emissions, $\mathrm{HC}, \mathrm{NO}_{\mathrm{x}}$ and particulates.

\section{Forced Induction}

In order to support the growing demand for more energy efficient, low carbon emission vehicles, manufacturers of forced induction systems, particularly for passenger cars and commercial vehicles, are being asked to provide more compact, higher efficiency systems that are both durable and affordable.

Forced induction, achieved by both turbocharging and supercharging, allows an engine to burn more fuel and air mixture by packing more oxygen molecules into the existing cylinders. Thus, the engine is able to deliver more power output per combustion stroke.

Forced induction is a key strategic technology for engine downsizing, permitting a small displacement engine to deliver a power output similar to larger naturally aspirated engines, as well as downspeeding, permitting the same power output with lower engine speed. Friction reduction and further improvement of thermodynamic efficiency at high specific loads are the drivers for this development.

Figure 1 Fuel consumption/emissions 


\section{Turbocharger}

A turbocharger is a device that uses the energy of exhaust gases emitted from an engine to compress the air going into the engine.

The core of a turbocharger is a rotating shaft coupling two wheels, a turbine wheel and a compressor wheel. The rotation of the shaft is supported by a bearing system.

The turbine wheel is positioned in the exhaust stream of the internal combustion engine. The exhaust gas from the cylinders passes through the turbine blades, causing the turbine to spin. The more exhaust gas that goes through the blades, the faster they spin.

The compressor wheel is positioned before the air intake to the cylinders and through rotation of the shaft supplies compressed air to the combustion cycle by increasing the number of the oxygen molecules.
Conventional bearing systems associated with turbochargers are oil film based. The shaft and wheel assembly is supported by a controlled oil film thickness to facilitate both rotation and ensure dynamic stability at very high speeds.

Advantages of ball rolling element bearing turbochargers over the conventional oil film turbocharger bearing systems originate from the fundamental change in the friction mechanism present in the system. Multiple rolling elements replace a thin oil film under high-shear conditions, significantly reducing system friction. This results in a significant improvement in system friction at operating temperature (typically up to $50 \%$ ) and even greater improvements during the first minute of an engine cold start (Figure 2).

With the more conventional oil film turbocharger bearing systems, the oil is very viscous in cold conditions. At this time, the viscous drag of the bearing system prevents the effective rotation of the shaft and hence does not supply

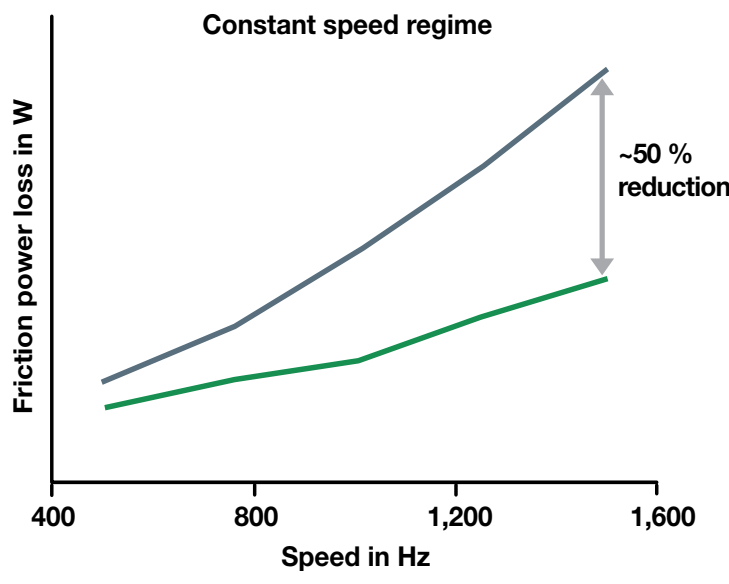

\section{- Plain bearing}

- Ball bearing

Source: Honeywell Turbo Technologies

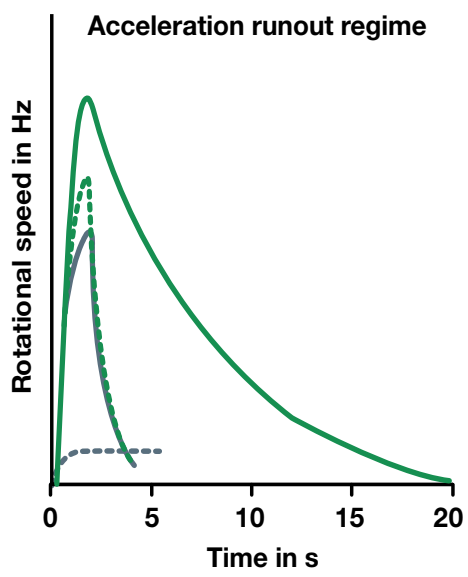

- Plain bearing at $20^{\circ} \mathrm{C}$

- Ball bearing at $20^{\circ} \mathrm{C}$

-- Plain bearing at $-20^{\circ} \mathrm{C}$

-- Ball bearing at $-20^{\circ} \mathrm{C}$

Figure 2 Friction loss benefits for ball bearing turbochargers 


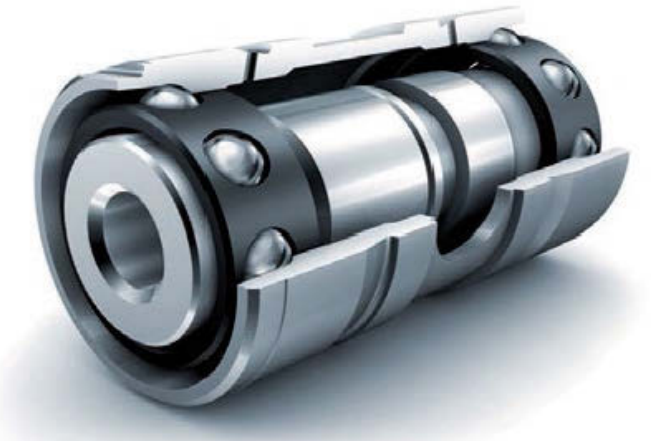

Figure 3 Schaeffler ball bearing cartridge

sufficient boost air to the combustion process. This means reduced power output and increased emissions. However, with ball bearing turbochargers the fundamental frictional change means that the flow of the exhaust gas, even at cold start, is sufficient to provide rotation to the shaft so that the compressor wheel can provide the necessary boost air to the engine system immediately. This results in a more energy efficient system with reduced emissions and also means that the driver experiences increased engine torque from the very beginning of the drive.

Turbocharger studies have shown that the 'ball bearing effect' is most pronounced at low engine speeds, just where a downspeeding or downsizing concept needs the most help from the turbocharger system. For engine operation the reduced bearing friction results in higher turbocharger speeds for the lower engine speed conditions mentioned above. Specifically, in the event of a sudden engine load request during idle or low load conditions, the increased turbocharger speed results in a significant improvement of engine response due to the turbocharger's instantaneous ability to supply compressed air. It is not only the ability to avoid the "turbo lag" that is striking but also the improvement of raw emission quality due to improved fresh air supply.

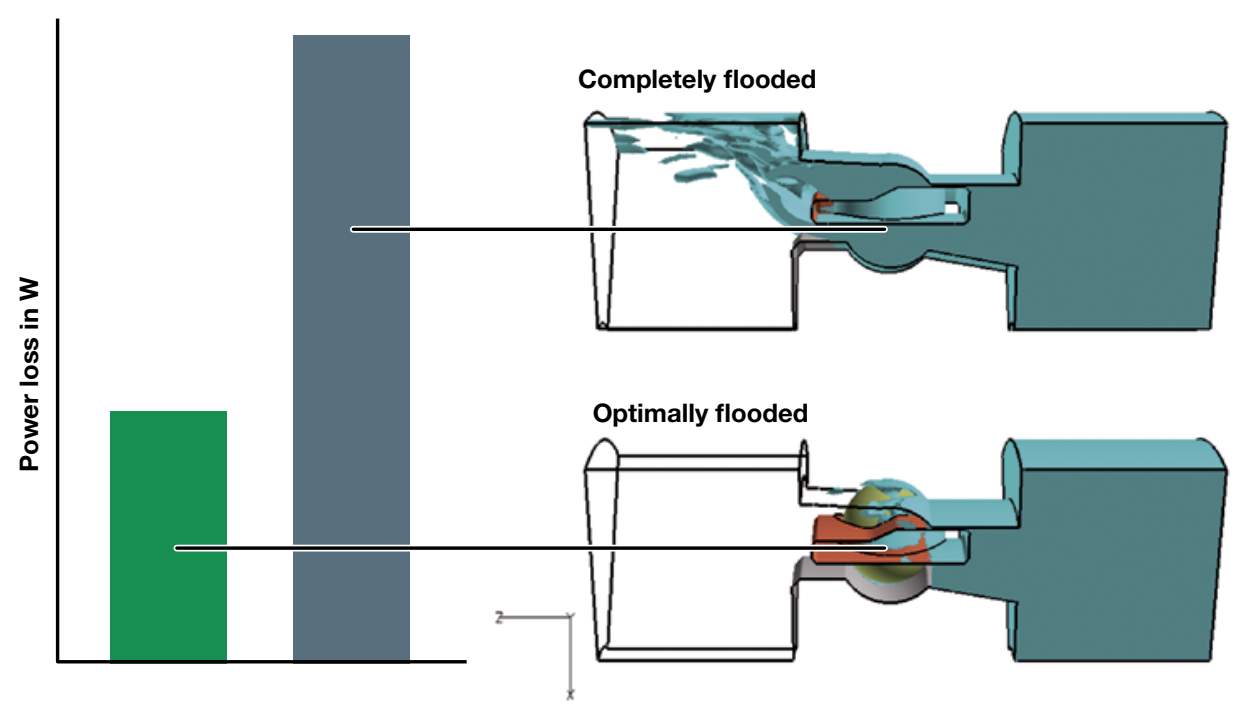

Figure 4 Friction power loss at various oil flow regimes 

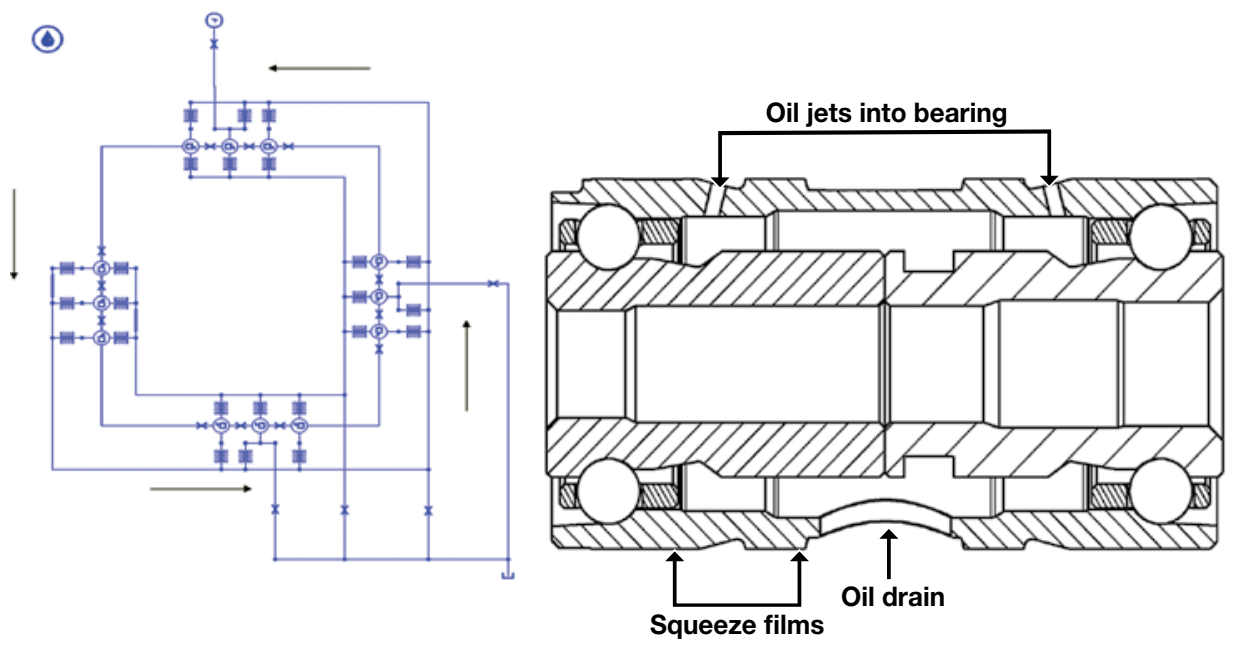

Figure 5 1-D CFD simulation of oil path (left); cross section of bearing with oil duct features (right)

\section{Schaeffler ball bearings for Turbocharger}

Schaeffler ball bearings for turbochargers (Figure 3) are of the angular contact type. Typically, these bearings utilize ceramic balls, cages, anti-rotation devices, an outer ring, a compressor side inner ring, a turbine side inner ring and a series of oil duct features for lubrication, cooling and for supplying the squeeze film damper areas.

Ball bearings for turbochargers rotate at very high rotational speeds. If the common characteristic speed value of bearings is considered, taking diameter and rotational speed $\left(n \cdot d_{m}\right)$ into account, turbocharger bearings run six times faster than any other bearing in a vehicle. By speed value, they compete with the peak of jet engines and textile machines. For these high speed conditions, requirements for lubrication are delicate: Sufficient lubricant must be provided at all times, but an excess of it might rapidly result in significant churning losses (Figure 4). Hence for the Schaeffler ball bearing cage, consideration was given to the design of the internal surfaces and component geometries.

As the ball bearing cartridge represents a single component of a larger system, we must take a closer look at the entire system and mutual effects.

The oil flow to the turbocharger (Figure 5), for both the oil film and the ball bearings, must also provide squeeze film damping. A squeeze film is a viscous fluid zone which provides structural isolation between elements, reduces the amplitude of rotor response to imbalance and also suppresses rotor-dynamic instability.

The entire fluid path, and necessary uses, can be simulated and fine tuned according to the ultimate performance requirements for the full range of temperatures.

A ball bearing can be understood as a series of springs of known, predictable stiffness. However, once coupled to the shaft, the wheels and the housing of the 


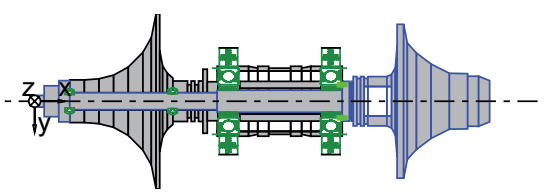

Press-fit

(shaft, inner ring)

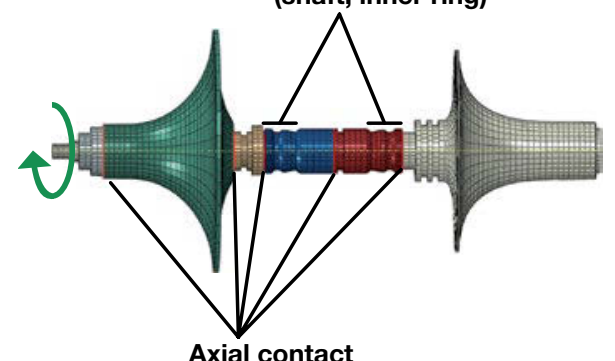

Axial contact

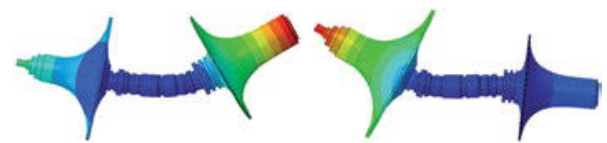

Figure 6 Bearinx model, multi-body structure, modal shapes

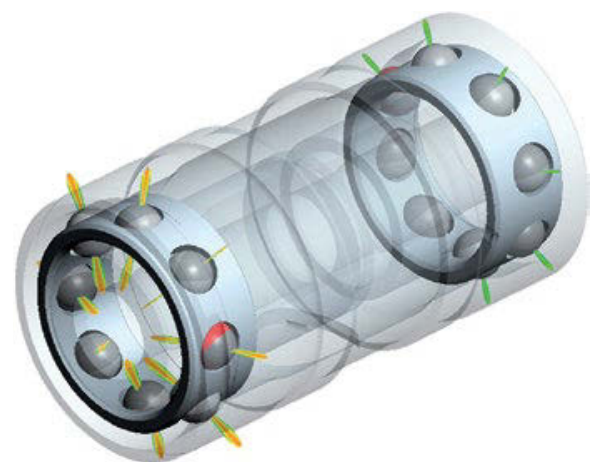

Contact pressure

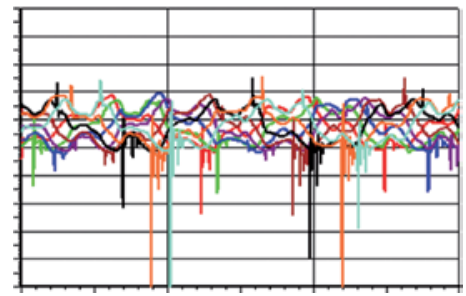

turbocharger and then revved at very high speed, the bearing must work well in the system.

The influence of the dynamic system must be considered. The radial load applied to the bearing typically comes from the residual imbalance. Here the interaction of the various system components comes into play as the structural stiffness of the shaft wheel assembly, the bearing stiffness as well as the properties of the squeeze film surrounding the bearing influence the bearing loads. At very high rotational speeds that are known to have a critical effect on shaft deflection this can cause damage to the internal kinematics of the bearing design and ultimately affect the life of the system (Figure 6). The axial load component is generated from "gas" pressure loading forces of the compressor or turbine wheel.

Once we consider the rotational speeds and modal shapes, operational temperatures and loads, we are better able to un-

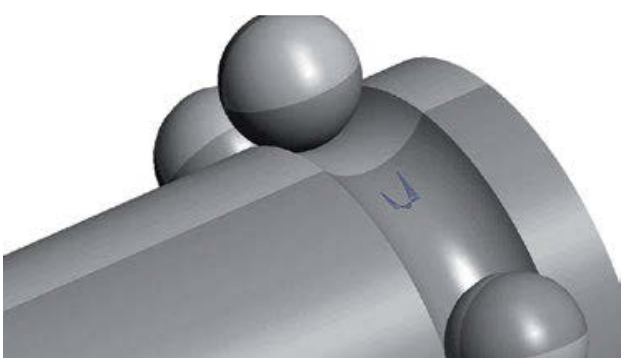

Shaft displacement

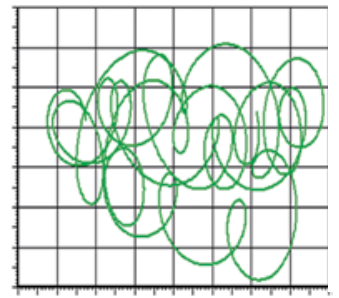

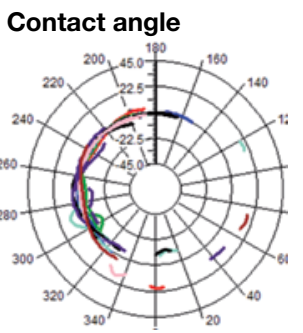

Figure 7 CABA 3D bearing simulation 


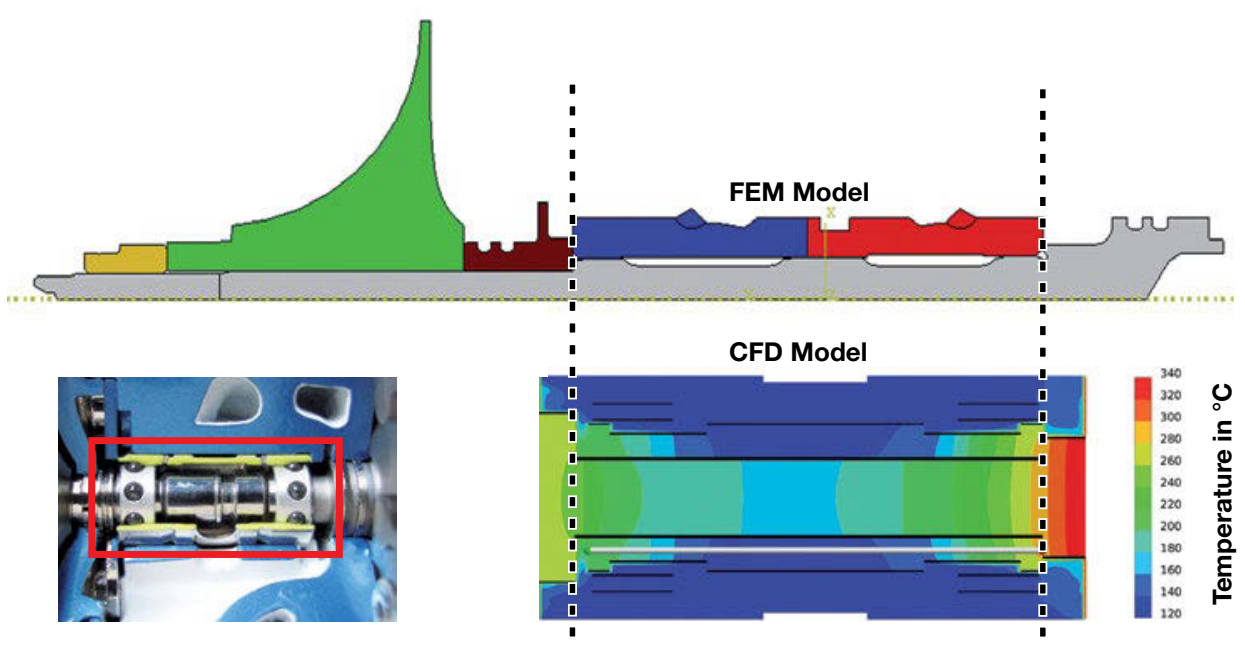

Figure 8 Combined FEM-CFD thermal analysis

derstand the internal kinematics of the actual bearing system.

The motion of the balls, their interactions with the raceways and the cages have a very complex relationship. Using special purpose simulation tools such as Schaeffler's CABA 3D, tailored to the requirements of bearing analysis, this motion can be computed and detailed results on the existence, location, extension and load in each individual contact between the components of the bearing can be obtained (Figure 7). This variety of results can be combined to achieve a detailed understanding of the bearing. Hence, the bearing system can be designed for optimal performance, life expectancy, reduction of friction and materials sensitivity.

Turbochargers must operate in extreme temperatures. We have already considered cold starts with regard to friction reduction and should now explore the hot running requirements. The turbine wheel is driven by the exhaust gases of the internal combustion engine and is therefore exposed to exhaust gas tem-

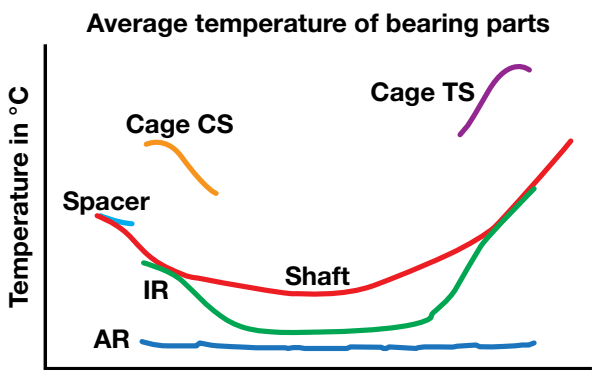

Position in axial direction

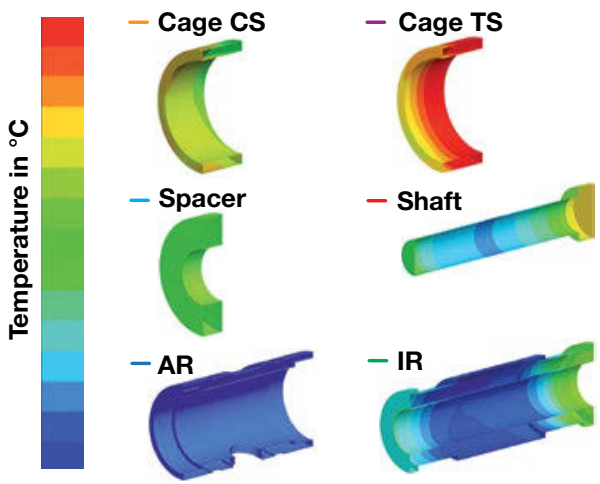

Figure 9 Temperature distribution in the bearing parts 
peratures. In normal operating cycles this high temperature ultimately flows by means of thermal conduction through the multibody system to the ball bearing where it is led away by oil flow. More critical are the thermal shut down conditions where the oil flow is stopped.

In normal operation, the bearing can reach temperatures of around $300{ }^{\circ} \mathrm{C}$ on the turbine side, whereas in thermal shutdown conditions, these bearings can even reach temperatures of up to $400^{\circ} \mathrm{C}$.

Applying both CFD and FEM to the problem (Figure 8), we can obtain thermal characteristics (Figure 9) with regard to radial and axial growth parameters in addition to the composition or thermal conditioning of the material growth.

There is a significant temperature difference across the components, and the consequences must be taken into account in the internal bearing design as well as the material characteristics. The bearing system must withstand extreme temperatures and extreme running speeds and be durable for the long term operation of the sys- tem. It is therefore necessary to select the materials very carefully for the relevant application environment.

\section{Outlook}

The year 2014 signifies a great achievement for turbocharger ball bearings supplied by Schaeffler and its group of companies.

For 10 years, Schaeffler has been leading the way in the development and supply of low-friction double row angular contact ball bearings for turbocharger technologies. During this time, we have perfected our application analysis, design tools and manufacturing methods. These precision ball bearings have helped set new turbocharger performance benchmarks for the future, particularly in the passenger car, light duty and heavy duty truck markets, and this year we will deliver our 1 millionth ball bearing cage for turbocharger applications in this sector.

Open Access. This chapter is distributed under the terms of the Creative Commons Attribution Noncommercial License, which permits any noncommercial use, distribution, and reproduction in any medium, provided the original author(s) and source are credited. 